\title{
Bioinformatics analysis and characterization of a secretory cystatin from Thelohanellus kitauei
}

\author{
Fengli Zhang ${ }^{1}$, Yalin Yang ${ }^{2 *}$, Chenchen Gao ${ }^{1}$, Yuanyuan Yao ${ }^{1}$, Rui Xia', Juan Hu${ }^{1}$, Chao Ran ${ }^{2}$, Zhen Zhang ${ }^{2}$ \\ and Zhigang Zhou ${ }^{1 *}$
}

\begin{abstract}
Thelohanellus kitauei, is a member of obligate parasitic myxozoans, which causes intestinal giant-cystic disease of common carp (Cyprinus carpio) and has resulted in significant economic losses in carp farms. Cystatin secreted by parasites can regulate the immune response of host to facilitate parasite's survival. In this study, the secretory TK-cystatin gene, encoding a protein of 120 amino acid residues (13.65 kDa), was cloned from T. kitauei genome. Phylogenetic analysis showed that TK-cystatin gene is closely related to the cystatin-A from Hydra vulgaris. Multiple sequence alignment revealed that TK-cystatin had three conserved motifs: N-terminal $\mathrm{G}^{19} \mathrm{G}^{20}, \mathrm{Q}^{73} \mathrm{WAG}^{77}$, and C-terminal $\mathrm{L}^{102} \mathrm{P}^{103}$. Molecular docking between TK-cystatin and three cysteine proteases showed a lower binding energy $(-13 \mathrm{KJ} / \mathrm{mol})$ with cathepsin $L$ whereas a higher binding energy $(-8.6 \mathrm{KJ} / \mathrm{mol})$ with cathepsin $\mathrm{B}$. TK-cystatin gene was expressed in Escherichia coli. Activity assays revealed that TK-cystatin has stronger inhibitory activity on endopeptidases (papain and cathepsin L) and weaker inhibitory activity on exopeptidase (cathepsin B). TK-cystatin was stable under the condition of acidity or alkalinity or below $57^{\circ} \mathrm{C}$. This study laid a foundation for the design and development of the anti-T. kitauei vaccine in carp culture in the future.
\end{abstract}

Keywords: TK-cystatin, Thelohanellus kitauei, Bioinformatics analysis, Protease inhibitor, Inhibitory activity, Molecular docking

\section{Introduction}

Myxozoans, a group of obligate parasitic metazoans that are important for pathogenic effects on freshwater and marine fish, were reported in various countries of the world (Zhao et al. 2016). A number of myxozoans including Thelohanellus kitauei preferentially infects the intestine of host, and causes intestinal giant-cystic disease of farmed carp (Gómez et al. 2013). The T. kitauei parasites generally inhabit the host gut submucosa and mucosa layer of the intestines, and form cysts through continuous proliferation, which seriously damage the intestinal structure of the cultured carp, resulting malnutrition

\footnotetext{
*Correspondence: yangyalin@caas.cn; zhouzhigang03@caas.cn 1 Sino-Norway Fish Gastrointestinal Microbiota Joint Lab, Feed Research Institute, Chinese Academy of Agricultural Sciences, Beijing 100081, China ${ }^{2}$ Key Laboratory for Feed Biotechnology of the Ministry of Agriculture, Feed Research Institute, Chinese Academy of Agricultural Sciences, Beijing 100081, China
}

and the gradual weight loss and high mortality (Shin et al. 2011; Ye et al. 2017). Cyprinus carpio accounts for the largest proportion of all farmed freshwater fish and has a high production in China. However, approximately $20 \%$ of farmed carps were killed by the disease caused by T. kitauei in 2010, directly causing an economic loss of about 50 million dollars (Yang et al. 2014). However, due to its complicated life cycle (between fish and annelids), the infection model of $T$. kitauei was very difficult to establish in laboratory culture conditions. Therefore, the current research on T. kitauei was just focused on morphological research, pathological diagnosis and phylogenetic position (Eszterbauer et al. 2006; Liu et al. 2014). Our group firstly sequenced the genome and transcriptome of T. kitauei and found that abundant secretory proteases and protease inhibitors may be related to nutrient digestion and immune evasion of parasites (Yang et al. 2014). Research on the characterization of these
Springer Open (c) The Author(s) 2020. This article is licensed under a Creative Commons Attribution 4.0 International License, which permits use, sharing, adaptation, distribution and reproduction in any medium or format, as long as you give appropriate credit to the original author(s) and the source, provide a link to the Creative Commons licence, and indicate if changes were made. The images or other third party material in this article are included in the article's Creative Commons licence, unless indicated otherwise in a credit line to the material. If material is not included in the article's Creative Commons licence and your intended use is not permitted by statutory regulation or exceeds the permitted use, you will need to obtain permission directly from the copyright holder. To view a copy of this licence, visit http://creativeco mmons.org/licenses/by/4.0/. 
proteases and protease inhibitors would pave the way for the parasite control.

Cystatin, known as cysteine protease inhibitor, was able to regulate many biological processes, and could suppress the host's immune response to facilitate pathogen's survival. Sialostatin, a cystatin from hard tick, could significantly inhibit the maturation of dendritic cells and proliferation of Ag-specific T cell (Sá-Nunes et al. 2009). OmC2 derived from soft tick could suppress the host's adaptive immune response by reducing inflammatory cytokines and proliferation of antigen presenting cell (Salát et al. 2010). Onchocystatin could not only significantly induce the production of anti-inflammatory cytokine IL-10, but could also inhibit the synthesis of proinflammatory Th1-type cytokines and the differentiation and proliferation of regulatory Th1 cells, there by reducing the host's immune killing effect on parasites (Schönemeyer et al. 2001). Wang et al. (2017) studied the immuno-regulatory effects of cystatin from Haemonchus contortus on goat monocytes and found that it could significantly inhibit the activity of goat monocytes and reduce production of the proinflammatory cytokines TNF- $\alpha$, IL-1 $\beta$, while significantly increasing secretion of IL-10. At the same time, cysteine protease inhibitors affected the connection between antigenic peptides and major histocompatibility complex class II (MHC-II) in the host by inhibiting the corresponding protease, which prevented the host from presenting the parasite antigen (Turk et al. 2001; Vray et al. 2002; Wang et al. 2017). Whether the structural features of a secretory cystatin (named as TK-cystatin, GenBank accession number: KII69890.1) in T. kitauei with high-expression level in the myxospore stage were similar to these inhibitors, and whether it could inhibit host cysteine proteases and plays similar roles?

In this study, the TK-cystatin gene was cloned from $T$. kitauei genome. Primary structure, the evolutionary relationship, conserved regions/domains, 3D structure and moculear docking of TK-cystatin were investigated by comprehensive bioinformatics analysis. TK-cystatin gene was expressed in Escherichia coli and its inhibitory activity and stability was characterized. This study would provide the basis for parasite-host interaction mechanism and practical applications in immunotherapy.

\section{Materials and methods}

\section{Collection of $T$. kitauei from infected C. carpio}

T. kitauei-infected C. carpio samples were collected from Wuqing, Tianjin, China. The infected $C$. carpio with the parasite had no special clinical sign beside swelling belly and it's intestine contained multiple cysts. Extraction of the parasites was applied by previous method (Yang et al. 2014). Purified parasites were further filtrated through $40 \mathrm{~mm}$ nylon meshes and washed with sterile distilled water, then determined by light microscopy or stored at $-80{ }^{\circ} \mathrm{C}$ until to use. The protocol of extraction of genomic DNA was followed by previous method (Yap and Thompson. 1987). The identified 18S rDNA of the parasites (GenBank accession number: HQ115585) was amplified using specific primers (Forward primer: 5'-ATGTTGTGCTTGGTGACATTCATATTTTTTG-3'; Reverse primer: 5'-TCAATATCCCGACACGCCACC$\left.3^{\prime}\right)$. The PCR product was confirmed by DNA sequencing.

\section{Cloning of TK-cystatin gene}

Total RNA of purified T. kitauei was extracted using Trizol RNA extraction reagent, according to Jaroenlak's method (Jaroenlak et al. 2018). The extraction used as template RNA in reverse transcription reactions to produce cDNA using an oligo-dT primer, which subsequently used as the template for cloning the TK-cystatin gene. According to our early analysis of T. kitauei genome, the full-length of TK-cystatin gene (GenBank accession number: KII69890.1) was amplified by the specific primer pairs (Forward primer: 5'-ATGTTGAAG GCGGCTGTC-3'; Reverse primer: 5'-TCATTGCGG ATGTTTTGTATCA-3 ${ }^{\prime}$ ). PCR was performed with the following parameters: initiation denaturation at $94{ }^{\circ} \mathrm{C}$ for $3 \mathrm{~min}$, followed by 30 cycles of $94{ }^{\circ} \mathrm{C}$ for $30 \mathrm{~s}, 53{ }^{\circ} \mathrm{C}$ for $30 \mathrm{~s}$, and $72{ }^{\circ} \mathrm{C}$ for $1 \mathrm{~min}$, and a final extension at $72{ }^{\circ} \mathrm{C}$ for $2 \mathrm{~min}$. The PCR products were confirmed by DNA sequencing.

\section{Characterization and phylogenetic analysis of TK-cystatin}

Bioinformatic analysis of the TK-cystatin was performed. The ExPASy Online tool (https://web.expasy.org/protp $\operatorname{aram} /)$ was used to predict the theoretical isoelectric point (PI), the molecular mass, and stability coefficient. NetOGlyc 4.0 and NetNGlyc 1.0 (Steentoft et al. 2013; Gupta et al. 2004) were used to predict potential O-glycosylation site and $\mathrm{N}$-glycosylation site. PROSITE (https ://prosite.expasy.org/cgi-bin/prosite/ScanView.cgi?scanf ile $=323446234217 . \mathrm{scan} . \mathrm{gz}$. was used to predict potential phosphorylation site (Sigrist et al. 2012).

For the phylogenetic analysis, a phylogenetic tree of TK-cystatin was constructed by using neighborjoining (NJ) method with MEGA 7.0 (Saitou and Nei 1987; Kumar et al. 2016). The evolutionary distances as described by Nei et al. (2000) were computed using the p-distance method. Test of the reality of phylogeny tree was used bootstrap method with 500 bootstrap replicates (Felsenstein 1985).

\section{The 3D structure and molecular docking of TK-cystatin}

The homology search of TK-cystatin protein was carried out by BLASTP, and the top seven hits of similar 
sequences from other species, such as cystatin-A from Hydra vulgaris (XP_012565994), cystatin-B from Oreochromis niloticus (XP_003439236), cystatin-A from Aotus nancymaae (XP_021529657), cystatin-A from Opisthocomus hoazin (XP_009930686), cystatin-B from Peromyscus maniculatus bairdii (XP_006989515), cystatin-A from Pelodiscus sinensis (XP_006124242), and cystatin-A from Chrysemys picta bellii (XP_023966898) were selected for multiple sequence alignment using ClusterW and Espritt 3.0.

Secondary and tertiary structures of TK-cystatin were predicted using Phyre2 (Kelley et al. 2015). Model quality of predicted 3D structure was evaluated by a Ramachandran plot using Procheck analysis tools (https://servicesn. mbi.ucla.edu/PROCHECK/) (Laskowski et al. 1993). Visualization and optimization of graphics of 3D structure was executed by the PyMOL Molecular Graphics System, Version 2.0 (DeLano 2002).

To study the inhibitory mechanism of TK-cystatin against three cysteine proteases, molecular docking analysis was performed using ZDOCK 3.0.2 (http://zdock .umassmed.edu/) (Pierce et al. 2014). Three cysteine proteases obtained from PDB database: papain (PDB ID: 1ppp), cathepsin L (PDB ID: 2NDQ), cathepsin B (PDB ID: 1GMY) were selected to dock with TK-cystatin. The structure of the predicted complex were analyzed by PDBepisa online website (https://www.ebi.ac.uk/pdbe/ pisa/), and the main interaction bonds were visualized in the PyMOL Molecular Graphics System, Version 2.0 (DeLano 2002).

\section{Heterogeneous expression and purification of TK-cystatin protein}

The TK-cystatin gene was inserted into pET28a expression vector through homologous recombination, and His-tag was introduced to the c-terminus of the TK-cystatin gene for purification. Two primer pairs, pET28aF (5'-AGAAGGAGATATACCATGTTGAAGGCGGCT GTCTTTC-3')/pET28aR (5'-TCAGTGGTGGTGGTG GTGGTGTTGCGGATGTTTTGTATCAAG-3') and TK-cystatinF (5'-CACCACCACCACCACCACTG-3')/ TK-cystatinR (5'-CATGGTATATCTCCTTCTTAAAGT TAAA-3 ${ }^{\prime}$ ) were used for amplifying the vector fragment and the target gene fragment, respectively. The PCRamplified DNA fragments were purified and assembled into recombinant pET28a_TK-cystatin plasmid by NEB/ NEBuilder ${ }^{\circledR}$ HiFi DNA Assembly Master Mix (New England Biolabs). The recombination product then was transformed into E. coli BL21 (DE3) and positive clones were determined by DNA sequencing using T7 universal primers. A single positive clone from overnight culture was transferred to $200 \mathrm{~mL}$ LB medium with kanamycin $(100 \mu \mathrm{g} / \mathrm{mL})$ according to the ratio of $1: 100$. When the
$\mathrm{OD}_{600}=0.6-0.8$, induced with various concentrations of IPTG (isopropyl $\beta$-D-1-thiogalactopyranoside) at $16{ }^{\circ} \mathrm{C}$ for overnight. The culture was centrifuged at $12,000 \times g$ at $4{ }^{\circ} \mathrm{C}$ for $10 \mathrm{~min}$, the bacterial cells were harvested. TKcystatin protein was purified from recombinant cells using $\mathrm{Ni}^{2+}$-NTA affinity method as described by Huo et al. (2016), and was dissolved at $50 \mathrm{mmol} / \mathrm{L} \mathrm{NH}_{4} \mathrm{HCO}_{3}$ $(\mathrm{pH}=7.5)$ based on previous research (Keilova and Tomášek 1974). The purified protein was analyzed by $12 \%$ SDS-PAGE and identified using MALDI-TOF-MS.

\section{Inhibitory activity and stability of TK-cystatin}

To investigate the potential immune inhibitory function of TK-cystatin, the inhibitory activity of recombinant TK-cystatin protein was measured against three physiologically relevant peptidases including endopeptidases (papain from Carica papaya and cathepsin $L$ from human) and exopeptidase (cathepsin B from human). All the three proteases were purchased from Sigma-Aldrich (Chen et al. 2017; Coronado et al. 2017). Fluorescent short peptide substrates from Sigma-Aldrich(Z-PheArg-AMC for papain and cathepsin L, Z-Arg-Arg-AMC for cathepsin B) were diluted in DMSO for $1 \mathrm{mmol} / \mathrm{L}$ as stock concentration. The experiment was performed as previously described with some midifications (Coronado et al. 2017; Sun et al. 2013). Cysteine proteases $(0.15 \mu \mathrm{mol} / \mathrm{L}$ for papain, $0.026 \mu \mathrm{mol} / \mathrm{L}$ for cathepsin $\mathrm{L}$, $0.026 \mu \mathrm{mol} / \mathrm{L}$ for cathepsin B) in the incubation buffer $(100 \mathrm{mmol} / \mathrm{L}$ sodium acetate, $100 \mathrm{mmol} / \mathrm{L}$ sodium chloride, $1 \mathrm{mmol} / \mathrm{L}$ EDTA, $1 \mathrm{mg} / \mathrm{mL}$ L-cysteine hydrochloride, $0.005 \%$ tritonx-100, $\mathrm{pH}$ 5.5) were activated by pre-incubation in 96 well black microplate at $37{ }^{\circ} \mathrm{C}$ for $30 \mathrm{~min}$. After that, another two reactants, $10 \mu \mathrm{mol} / \mathrm{L} \mathrm{sub-}$ strates and an increasing-concentration gradient TK-cystatin, were added to each well of this microplate to a final volume of $200 \mu \mathrm{L}$. Subsequently, fluorescent products were measured with excitation at $360 \mathrm{~nm}$ and emission at $460 \mathrm{~nm}$ using fluorescence spectrometer (Bio Tek) every $30 \mathrm{~s}$ for 10-min reaction. Each reaction was performed in triplicate.

In order to further study the properties of TK-cystatin, the effects of temperature and $\mathrm{pH}$ on it were measured as descripted previously (Tzeng et al. 2002). The thermal stability of TK-cystatin was assessed by assay of TK-cystatin inhibitory activity against papain with the fluorescent substrate Z-Phe-Arg-AMC after preincubating at $25,37,47,57$, and $67^{\circ} \mathrm{C}$ for $1 \mathrm{~h}$ respectively. The stability of TK-cystatin at different $\mathrm{pH}$ values was determined by preincubating TK-cystatin in solutions with $\mathrm{pH}$ at 3.0 to 11.0 for $1 \mathrm{~h}$, followed by assay of TK-cystatin inhibitory activity against papain under standard conditions as described above. The buffers used were disodium 
bicarbonate-citrate buffer ( $\mathrm{pH} 3.0$ to 8.0 ) and sodium carbonate-sodium bicarbonate buffer (pH 9.0 to 11.0).

\section{Statistical analysis}

The activity of TK-cystatin protein was expressed as half maximal inhibitory concentration $\left(\mathrm{IC}_{50}\right)$. It based on real-time mean velocities and determined by nonlinear regression analysis. All statistical analyses were performed in GraphPad Prism Version 6 software (GraphPad Software Inc. San Diego, CA, USA).

\section{Results}

\section{Extraction and identification of T. kitauei}

Dissection of infected C. carpio revealed that T. kitauei was mainly located in the cysts on the surface of the host intestine. Light microscopy revealed that these spores were pyriform in shape having a pointed front and blunt rear end, and polar filaments were either coiled spirally in the polar capsules or extruded to parasites' surface (Fig. 1a). The size of $18 \mathrm{~S}$ rDNA product of the isolated parasites was nearly $1000 \mathrm{bp}$ in the agarose gel electrophoresis, which was consistent with its theoretical size (Fig. 1b), and it had 99\% identity to that of the T. kitauei (GenBank accession number: HQ115585). Combined with the morphological observations, the parasite was identified as T. kitauei.

\section{TK-cystatin sequence bioinformation analysis and its phylogeny}

The 363 bp full-length TK-cystatin gene encodes 120 amino acid residues with an estimated molecular mass of $13.65 \mathrm{kDa}$ and a theoretical $p \mathrm{I}$ of 6.97 predicted by the ProtParam (Fig. 2a). The low computed instability index (II) of TK-cystatin (15.82) indicated that the protein was stable. One potential $\mathrm{N}$-glycosylation site $\left(\mathrm{N}^{68} \mathrm{VKV}^{71}\right)$, one Casein kinase II phosphorylation site $\left(\mathrm{S}^{42} \mathrm{FKD}^{45}\right)$ and three protein kinase $\mathrm{C}$ phosphorylation site $\left(\mathrm{S}^{42} \mathrm{FK}^{44} 、 \mathrm{~S}^{52} \mathrm{FK}{ }^{54} 、 \mathrm{~T}^{91} \mathrm{AR}^{93}\right)$ in TK-cystatin were predicted by NetNGlyc 1.0 and PROSITE (Fig. 2b). It's predicted that secondary structure consisted of one $\alpha$-helices and four $\beta$-strand (Fig. 2b).

Phylogenetic analysis of cysteine protease inhibitors indicated that TK-cystatin was closely related to the cystatin-A of H. vulgaris cnidarian and cystatin-B of Oreochromis niloticusi (Fig. 3). Alignment with other cystatins indicated that TK-cystatin contained three conserved cystatin motifs (N-terminal $\mathrm{G}^{19} \mathrm{G}^{20}, \mathrm{Q}^{73} \mathrm{VVAG}^{77}$ motif and $\mathrm{C}$-terminal $\mathrm{L}^{102} \mathrm{P}^{103}$ ) critical to the biological function of cystatins (Fig. 4).

\section{D structure of TK-cystatin and molecular docking}

Aided by Phyer2, the stefin A of family Cystatins from Homo sapiens was used as the template [PDB ID: $\mathrm{d} 1 \mathrm{nb} 5 \mathrm{i}$, $2.4 \AA$ resolution; with $28.6 \%$ sequence identity to TKcystatin; (Jenko et al. 2003)] to predict the structure of TK-cystatin. The 3D structure model quality was evaluated by Procheck and visualized by PyMOL 2.0 (Fig. 5). The result showed that TK-cystatin had a typical wedgeshaped structure consisting of four anti-parallel $\beta$-sheets wrapping around a $\alpha$-helix that was almost perpendicular to the $\beta$-sheet direction on one side and extending antiparallelly by $8 \mathrm{C}$-terminal residues on the other side. $\mathbf{a}$

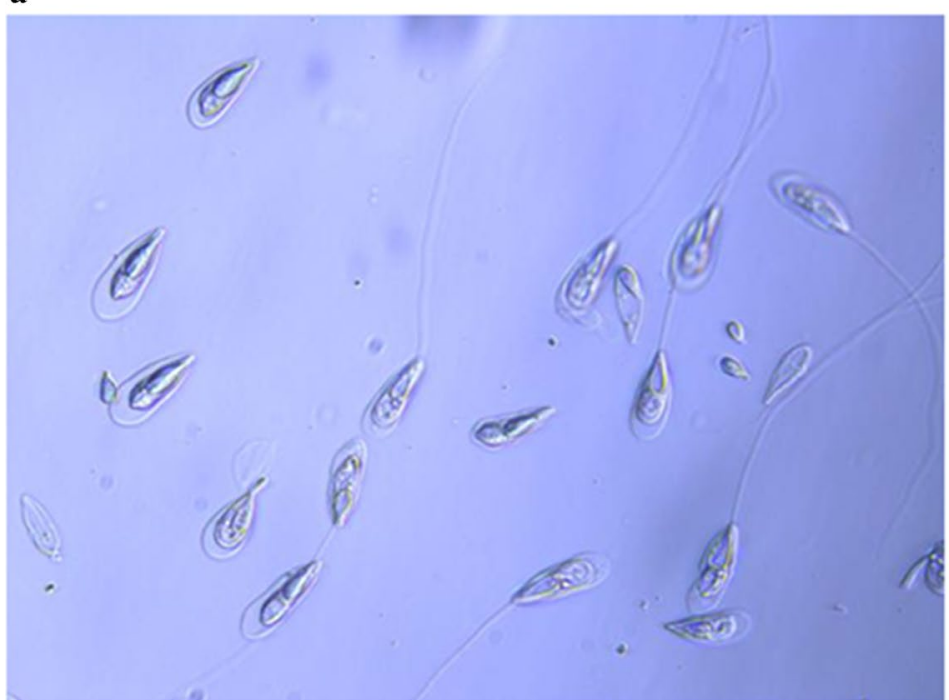

b

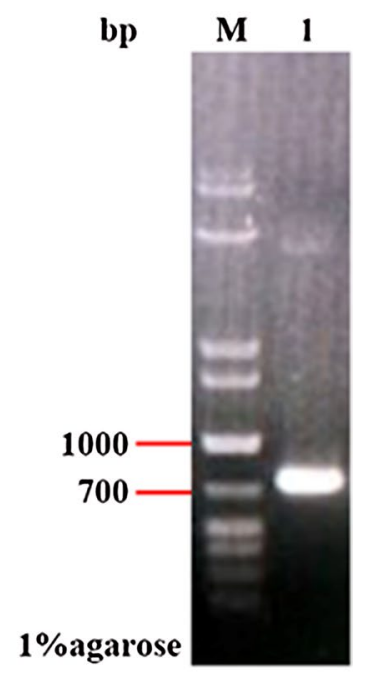

Fig. 1 Identification of T. kitauei. a Light micrograph of parasite spores stained with 1\% crystal violet solution (40X). b 18S rDNA PCR amplification product of T. kitauei. Line M: DNA marker (MD113, TIANGEN); Line 1: 18S rDNA 
a

TK-cystatin $\overbrace{}^{1} \overbrace{}^{66}$

b

10

20

40

TK-cystatin

MLKAAVFLFVIKM ID A L L G GWDKLHPLDDEEKKVFEHVKK F K G T H

TK-cystatin

50

60

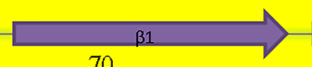

\begin{tabular}{l}
50 \\
I \\
\hline
\end{tabular}

70

80

90

K LY L K

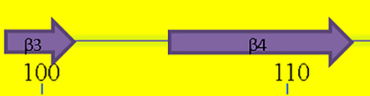

TK-cystatin

VFR GLPF D P VIEVEYLDTKHPQ

Fig. 2 Molecular characteristics of the amino acid sequence of TK-cystatin. a Domain of TK-cystatin, schematic view of the position of domains in the amino acid sequence (Lavender indicated the position of the cystatin domain in the sequence). $\mathbf{b}$ The secondary structure was marked in the amino acid sequence (Red and orange represented $\mathrm{N}$-glycosylation and phosphorylation sites; orange rectangular for a-helices, deep purple arrow for $\beta$-strand)

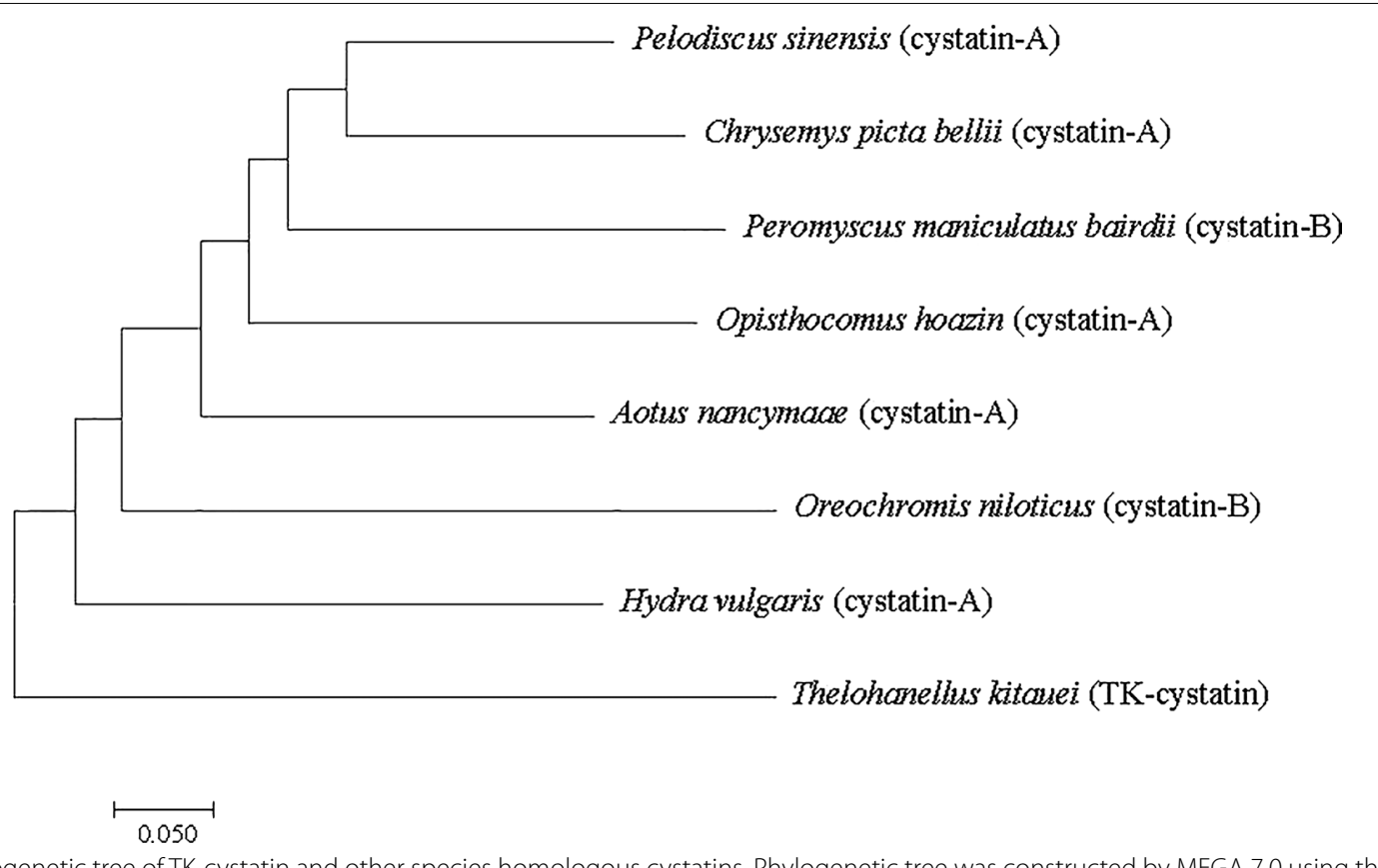

Fig. 3 Phylogenetic tree of TK-cystatin and other species homologous cystatins. Phylogenetic tree was constructed by MEGA 7.0 using the Neighbor-Joining algorithm. Bootstrap values from 500 replicates were given on the nodes

And this indicated that TK-cystatin had a similar structure to cystatinA. The $\mathrm{N}$-terminal conserved region, the hairpin loop 1 region (between $\beta 1$ and $\beta 2$ ) and hairpin loop 2 region (between $\beta 3$ and $\beta 4$ ) together formed the wedge-shaped edge, which was complementary to protease cleavage. The $\mathrm{N}$-terminal $\mathrm{G}^{19} \mathrm{G}^{20}$ was indispensable for the ability of the inhibitor to bind to the cysteine protease, with decreased affinity for inhibitor binding if deletion of this motif. The hairpin loop 1 containing the conserved QVVAG motif was a classic conformation of Cystatins. In TK-cystatin, the hairpin loop 2, formed by amino acid residues between two $C$-terminal $\beta$-sheet 


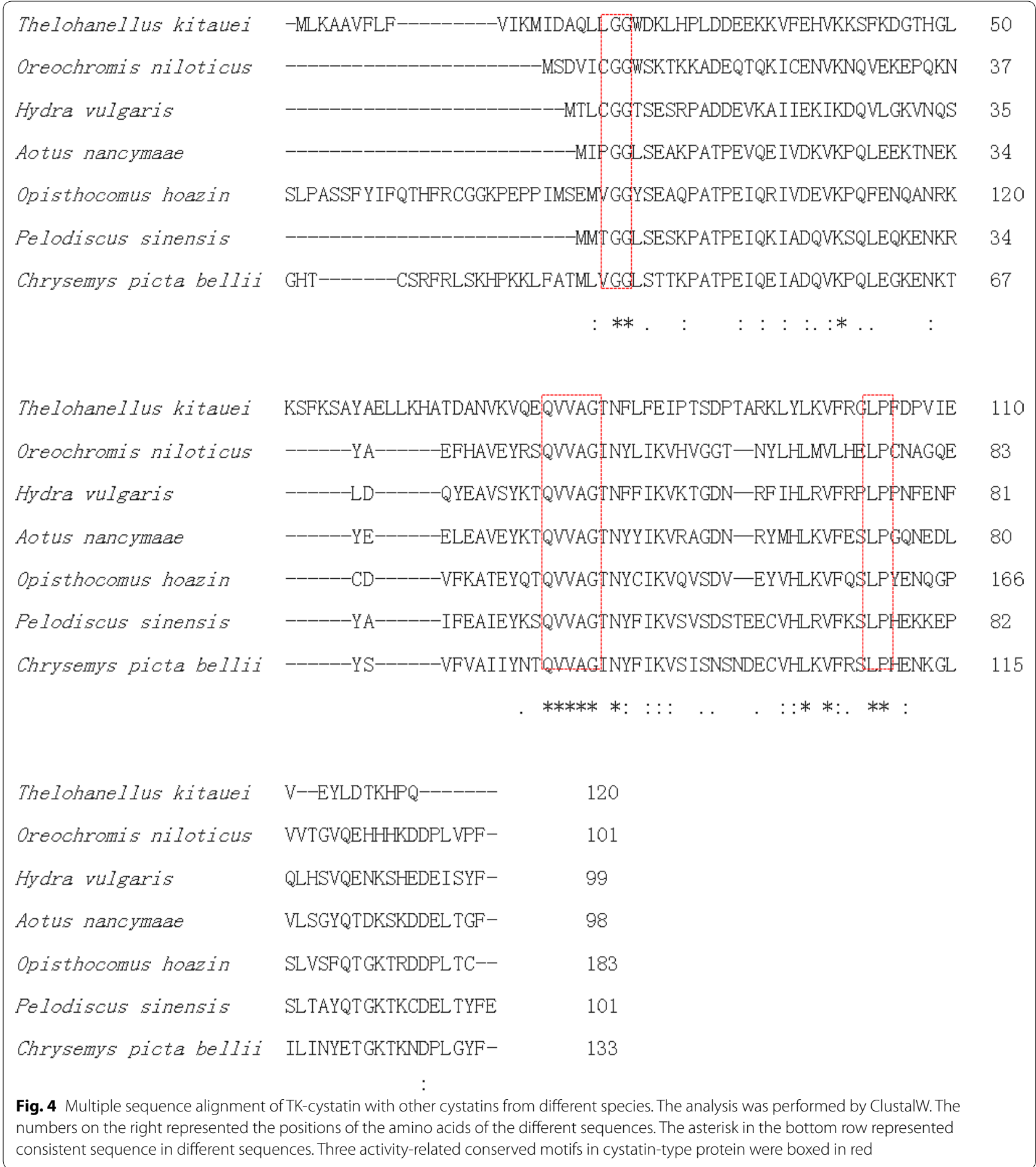

included conservative hydrophobic LP residues that was absence or replaced by PW in other cystatins (CuestaAstroz et al. 2014).

Molecular docking showed that the binding pattern between TK-cystatin and cysteine proteases was reminiscent of the shape of a "fork" that inserted into the active site of proteases from the top (Fig. 6). The loop1 of TK-cystatin was deeply inserted into shallow groove of $S$ ' subsite of proteases and interacted with the active site of the proteases. The other two conserved domains were 


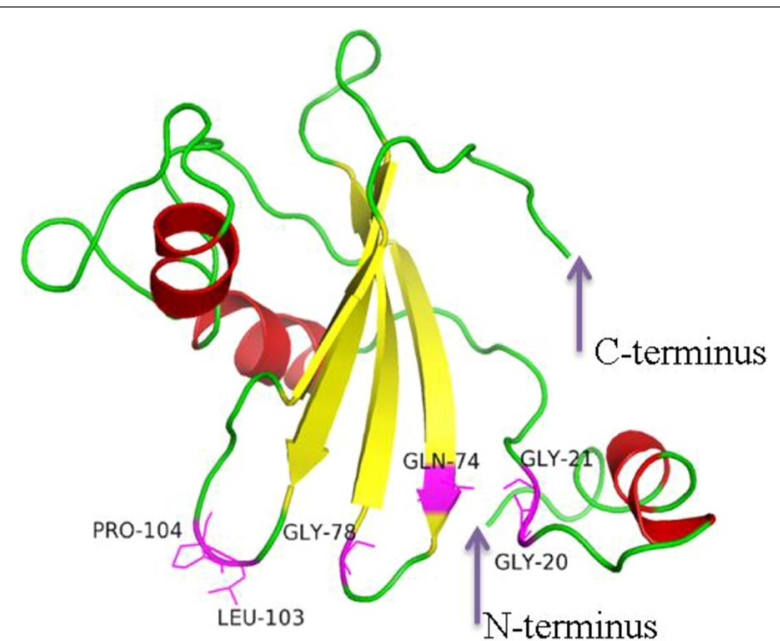

Fig. 5 Three-dimensional structure of TK-cystatin. Its 3D structure showed the typical wedge-shaped structure of cysteine protease inhibitor. The deep purple arrows pointed to the $\mathrm{N}$ - terminus or C-terminus of TK-cystatin. The position of the conserved motif in the 3D structure was shown by a magenta stick, next to the residue names

approximately served as a fixed function, particularly in cathepsin $B$, that interacted with the surface of the proteases by forming hydrogen bonds or salt bonds (Fig. 6c). In addition, some amino acid residues in the vicinity of the conserved sites also played an important role in the interaction with proteases (Fig. 6). Among three proteases docking with TK-cystatin, the interaction with cathepsin $\mathrm{L}$ had salt bonds in addition to hydrogen bonds (Fig. 6b). This may explain why the binding energy with cathepsin $\mathrm{L}$ was the lowest $(-13,-12.4$ and $-8.6 \mathrm{KJ} /$ mol for cathepsin L, papain and cathepsin B, respectively). The lower binding energy between cathepsin $\mathrm{L}$ and TK-cystatin indicated that the complex was more stable.

\section{Cloning and heterogeneous expression of TK-cystatin gene} TK-cystatin cDNA fragments were amplified by RTPCR from total RNA isolated from T. kitauei, a $363 \mathrm{bp}$ band was apparently in the agarose gel electrophoresis as shown in Fig. 7a. The purified PCR products of the TK-cystatin gene was sequenced and shared $99 \%$ identity with the corresponding predicted cystatin gene in T. kitauei genome. TK-cystatin gene was expressed in $E$. coli BL21(DE3). After induction with $0.1 \mathrm{mmol} / \mathrm{L}$ IPTG (final concentration) at $16{ }^{\circ} \mathrm{C}$ overnight, TK-cystatin was purified from the recombinant bacteria cell lysates by $\mathrm{Ni}^{2+}$-NTA affinity chromatography with $200 \mathrm{mmol} / \mathrm{L}$ imidazole elution buffer. The purified protein migrated to a predicted $\sim 10 \mathrm{kDa}$ band in $12 \%$ SDS-PAGE, was confirmed by western blot analysis with anti-His-tag mouse monoclonal antibody (Fig. 7b) and identified by MALDITOF-MS analysis with $90 \%$ peptide coverage.

\section{Inhibitory activity and stability of TK-cystatin}

Cystatin secreted by the parasite exerts immune evasion mainly by inhibiting the corresponding proteases in the host (Lecaille et al. 2002). Lysosomal cysteine proteases, especially cathepsin B, cathepsin L and cathepsin $S$, played an important role in immune regulation, such as could promote the binding of MHC-II molecules to antigens and affected the phagocytic activity of DC cells (Honey and Rudensky 2003; Smith et al. 2016). Cystatin could specifically inhibit papain and cathepsin protease activity through a strong binding interaction. In this study, the inhibitory activities of TK-cystatin against three standard proteases, including papain, cathepsin $\mathrm{L}$ and cathepsin B, were evaluated. TK-cystatin could inhibit the activities of all the three proteases in a dosedependent manner (Fig. 8). The values of half maximal inhibitory concentration $\left(\mathrm{IC}_{50}\right)$ for papain, cathepsin $\mathrm{L}$, cathepsin $\mathrm{B}$ inhibition by curve fitting were $0.8 \mu \mathrm{mol} / \mathrm{L}$, $0.175 \mu \mathrm{mol} / \mathrm{L}$, and $2.1 \mu \mathrm{mol} / \mathrm{L}$, respectively. $\mathrm{pH}$ and thermal stabilities of TK-cystatin were investigated. TKcystatin had lower activity stability near $\mathrm{pH}$ 7.0, higher stability at alkaline or acidic conditions, with highest stability at pH 11.0 (Fig. 9a). TK-cystatin was thermally stable below $57^{\circ} \mathrm{C}$ (Fig. 9b).

\section{Discussion}

In the absence of effective drugs to treat and prevent myxozoan infections, there is an urgent need to explore potential drug targets and develop effective and safe therapeutic drugs. Cysteine protease inhibitors are a major group of protease inhibitors secreted by parasites. They can regulate both the parasite and host cysteine protease activity and play important roles in parasite infection and immune suppression of their hosts (Lecaille et al. 2002; Norbury et al. 2012). rAv17, a cystatin C from Filarial nematodes, can markedly suppress mitogen-induced $\mathrm{T}$ cell proliferation and up-regulate IL-10 product (Hartmann et al. 1997). Nippocystatin from Nippostrongylus brasiliensis can down-regulate the process of antigen presentation in vitro and OVA-specific IgE levels in vivo, and mice with anti-nippocystatin antibodies became resistant to infection with $N$. brasiliensis to some extent (Dainichi et al. 2001). Therefore, cystatins are often used as candidate drug targets for parasite control (Lecaille et al. 2002; Smith et al. 2016).

Cysteine protease inhibitors can be divided into three major families, namely stefins (family 1) and cystatins (family 2) and kininogens (family 3). TK-cystatin has some important features of family-2 cystatins, such 


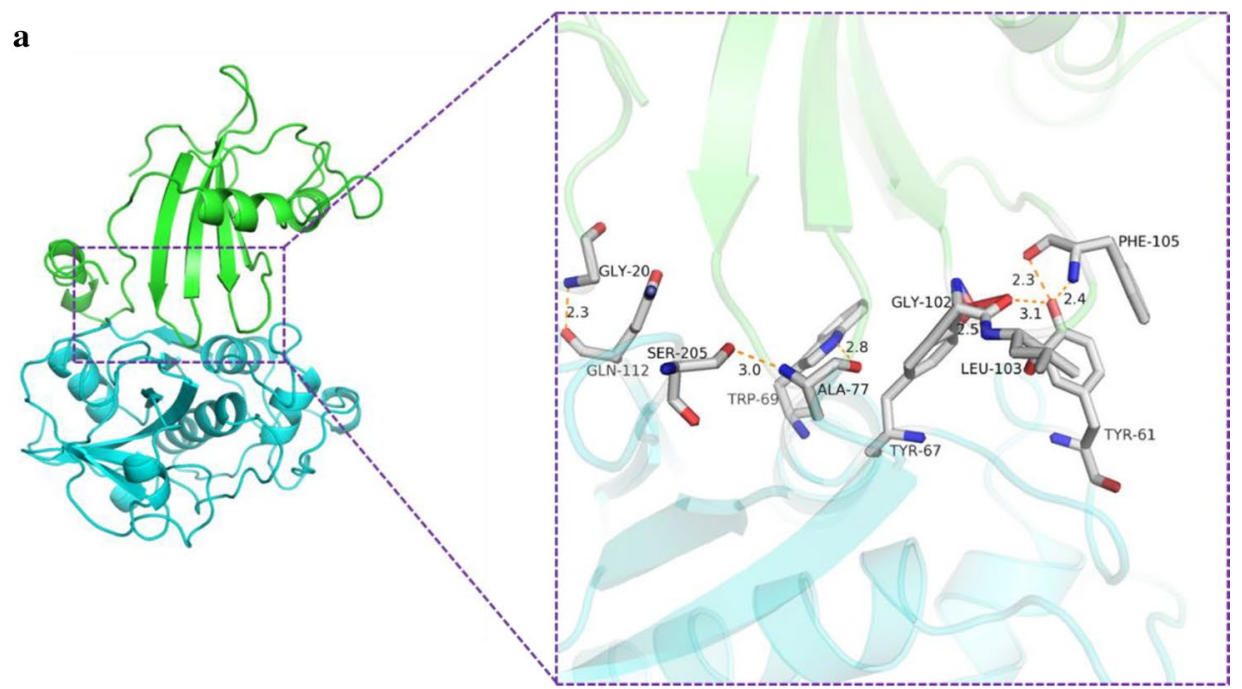

b
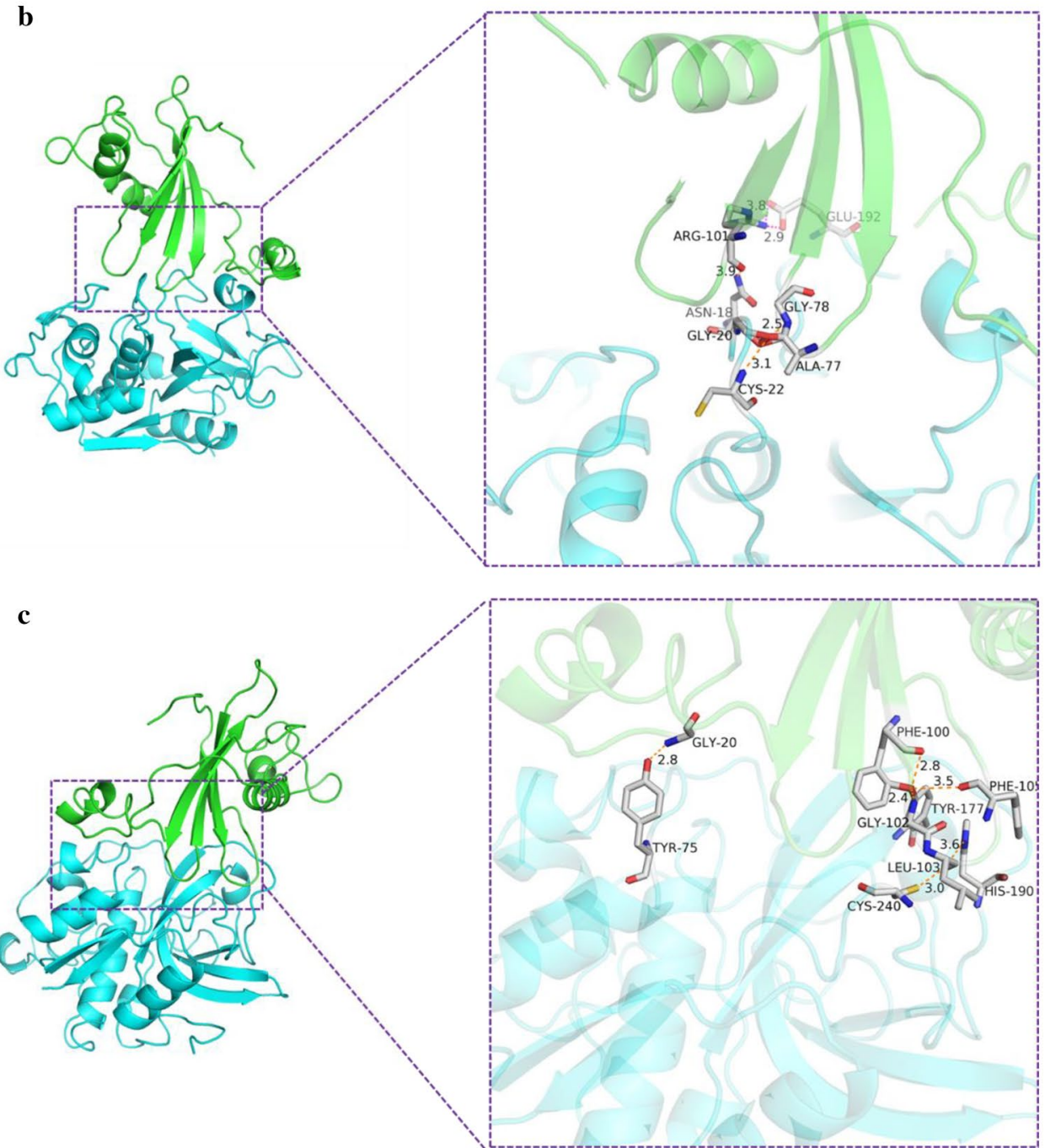

Fig. 6 Interaction between TK-cystatin and proteases. a papain (PDB ID: 1ppp), b cathepsin L (PDB ID: 2NDQ), c cathepsin B (PDB ID: 1 GMY). TK-cystatin was shown in green and three cysteine proteases were shown in blue. The hydrogen and salt bonds formed between the conserved site of TK-cystatin and three proteases were shown in orange and magenta, respectively 


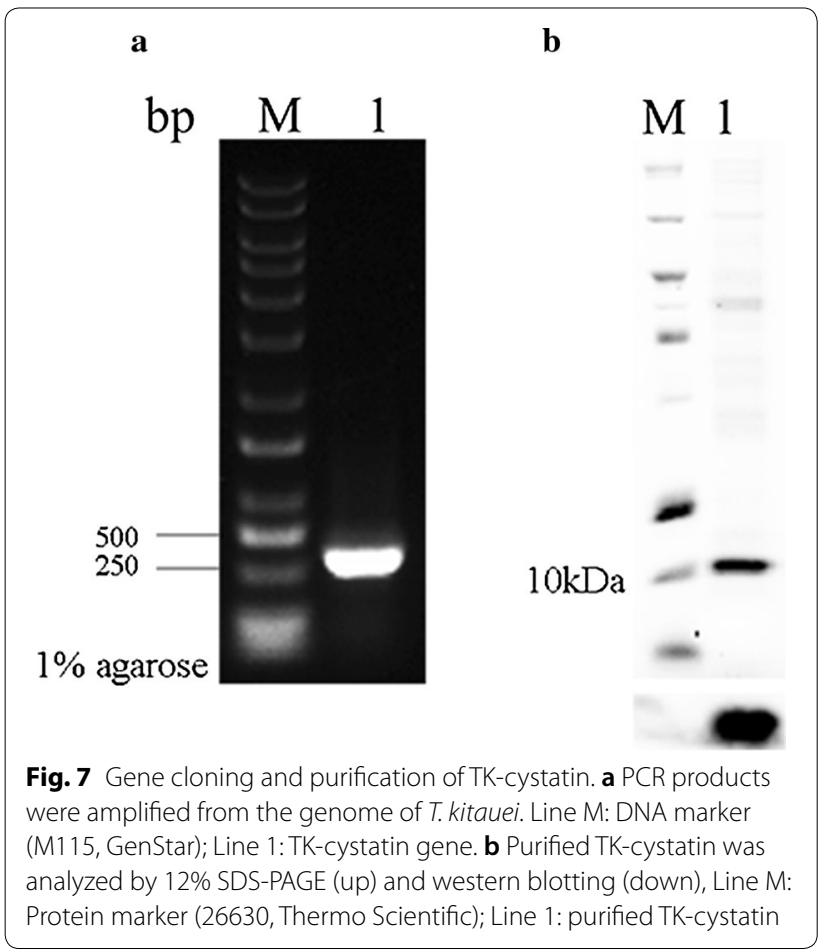

as secretory, small molecular weight, rich in phosphorylation sites, and conserved inhibitory regions (motifs of $\mathrm{G}^{19} \mathrm{G}^{20}, \mathrm{Q}^{74} \mathrm{VVAG}^{78}$ and $\mathrm{L}^{103} \mathrm{P}^{104}$ ). TKcystatin, however, lacks of disulfide bond, the $\mathrm{SND} / \mathrm{S}$ conserved motif relating to the inhibition of legumainlike proteases (Ilgová et al. 2017), and has relatively low sequence homology to other family-2 members. Therefore, TK-cystatin is a new member of cystatins (family 2).

With the in-depth studies on the morphology, development and evolution of myxozoa, more evidences support that myxozoans are multicellular metazoans and obligately parasitic cnidarian animals (Feng et al. 2014; Zhao et al. 2016). Our molecular evolutionary analysis of TK-cystatin revealed that it was most closely related to the cystatin-A of $H$. vulgaris, also provided evidence to support this view.

TK-cysatin has the inhibitory activity on both endopeptidases (papain and cathepsin L) and exopeptidase (cathepsin B), but the inhibitory activity of it against cathepsin $\mathrm{L}$ is 12 times higher than that against cathep$\sin \mathrm{B}$. This result is consistent with the conclusion of the
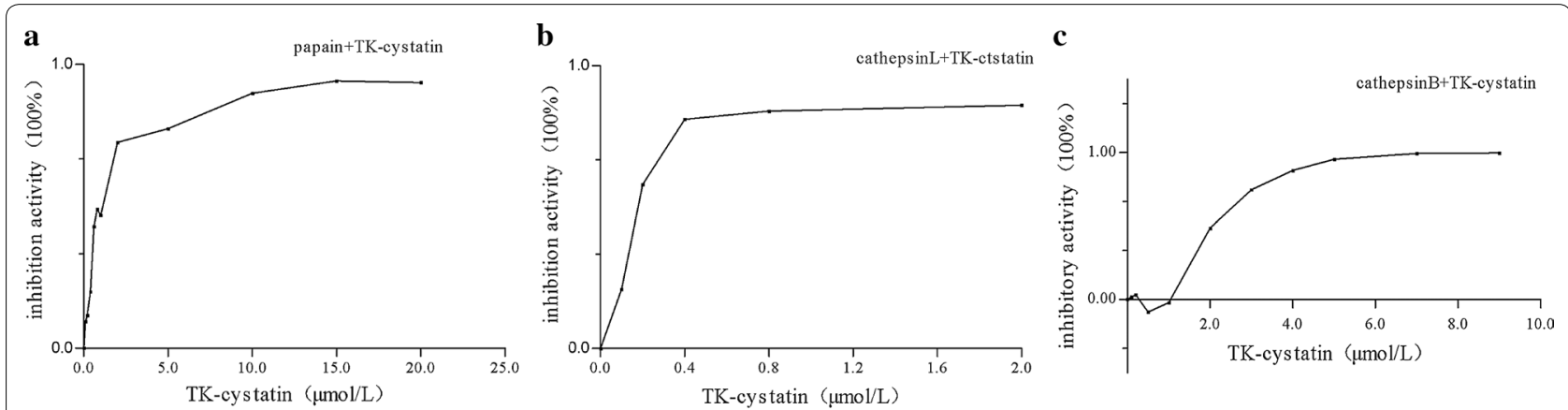

Fig. 8 Inhibitory activity of TK-cystatin against three cysteine proteases. Inhibitory activity of TK-cystatin against papain (a) and cathepsin L (b) and cathepsin B (c). The activity of non-inhibited enzyme (incubated without TK-cystatin) was taken as 100\% activity (Inhibitory activity: 0\%). Data shown were the average of three experiments
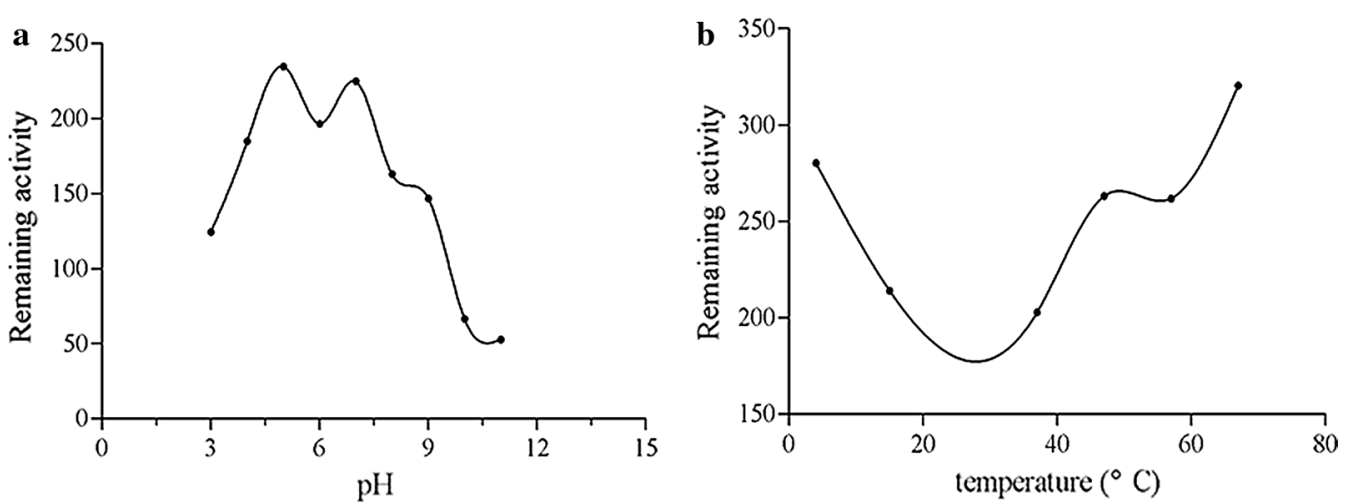

Fig. $9 \mathrm{pH}$ and thermal stability of TK-cystatin. TK-cystatin incubated at different pHs or temperatures for $1 \mathrm{~h}$ and assayed for residual inhibitor activity against papain at standard conditions. Data shown were the average of three experiments 
previous studies. Because compared to cathepsin L, cathepsin B contains an additional "occluding loop"structure in the $S^{\prime}$ region, which usually restricts the inhibitor from entering the active site (Turk et al. 2001; Fujishima et al. 1997). MHC-II-restricted antigen presentation plays a central role in the immune response against exogenous antigens. Cathepsin L, but not cathepsin B, degrades efficiently MHC-II-associated invariant chain, which makes MHC-II peptide-binding grooves fully exposed to facilitate binding with exogenous antigen polypeptides (Manoury et al. 2001; Medd and Chain 2000; Schierack et al. 2003). The results of this experiment show that TKcystatin has a stronger inhibitory activity on cathepsin L, indicating that the inhibitor may serve the parasite as a mean to evade the host's immune attack.

\section{Abbreviations}

RT-PCR: Reverse transcription-polymerase chain reaction; PCR: Polymerase chain reaction; MALDI-TOF-MS: Matrix-Assisted laser Desorption/lonization Time of Flight Mass Spectrometry; SDS-PAGE: Sodium dodecylsulphate polyacrylamide gel electrophoresis.

\section{Acknowledgements}

We thank Professor Jihong Liu Clarke for revising the article.

\section{Authors' contributions}

Paryicipated in research design: $F Z, Y Y, C G, Y Y$ and $Z Z$; Conducted experiments and performed data analysis: $F Z, Y Y, C G, Y Y, R X, J H, C R$, ZZ and ZZ; Wrote the manuscript or contributed to the manuscript: FZ, YY, CG, YY, RX and ZZ. All authors read and approved the final manuscript.

\section{Funding}

This work was supported by the key project of National Natural Science Foundation of China (Grant No. 31672294), the earmarked fund for Modern Agroindustry Technology Research System (SCGWZJ20201104-4), the Innovation Capability Support Program of Shaanxi (2018TD-021), and the Se-enriched Special Science and Technology Project of China Institute of Se-enriched Industry (2018FXZX02-04)

\section{Availability of data and materials}

All the data were presented in the main paper.

\section{Ethics approval and consent to participate}

The use of experimental commom carp in this study has been approved by the Animal Care and Use Committee of Feed Research Institute Chinese Academy of Agricultural Sciences (Beijing, China).

\section{Consent for publication}

Not applicable.

\section{Competing interests}

The authors declare that they have no competing interests.

Received: 2 May 2020 Accepted: 15 June 2020

Published online: 23 June 2020

\section{References}

Chen L, He B, Hou W, He L (2017) Cysteine protease inhibitor of Schistosoma japonicum - A parasite-derived negative immunoregulatory factor. Parasitol Res 116:901-908
Coronado S, Barrios L, Zakzuk J, Regino R, Ahumada V, Franco L, Caraballo L (2017) A recombinant cystatin from Ascaris lumbricoides attenuates inflammation of DSS-induced colitis. Parasite Immunol 39(4):e12425

Cuesta-Astroz Y, Scholte LL, Pais FS-M, Oliveira G, Nahum LA (2014) Evolutionary analysis of the cystatin family in three Schistosoma species. Front Genet 5:206

Dainichi T, Maekawa Y, Ishii K, Zhang T, Nashed BF, Sakai T, Takashima M, Himeno K (2001) Nippocystatin, a cysteine protease inhibitor from Nippostrongylus brasiliensis, inhibits antigen processing and modulates antigen-specific immune response. Infect Immun 69:7380-7386

DeLano WL (2002) The PyMOL molecular graphics system. http://www.pymol .org

Eszterbauer E, Marton S, Racz OZ, Letenyei M, Molnár K (2006) Morphological and genetic differences among actinosporean stages of fish-parasitic myxosporeans (Myxozoa): difficulties of species identification. Syst Parasitol 65(2):97-114

Felsenstein J (1985) Confidence limits on phylogenies: an approach using the bootstrap. Evolution 39:783-791

Feng JM, Xiong J, Zhang JY, Yang YL, Yao B, Zhou ZG, Miao W (2014) New phylogenomic and comparative analyses provide corroborating evidence that Myxozoa is Cnidaria. Mol Phylogenet Evol 81:10-18

Fujishima A, Imai Y, Nomura T, Fujisawa Y, Sugawara T (1997) The crystal structure of human cathepsin I complexed with e-64. FEBS Lett 407(1):47-50

Gómez D, Bartholomew J, Sunyer JO (2013) Biology and mucosal immunity to myxozoans. Dev Comp Immunol 43(2):243-256

Gupta R, Jung E, Brunak S (2004) NetNGlyc 1.0 Server. Center for biological sequence analysis, technical university of Denmark. http://www.cbs. dtudk/services/NetNGlyc

Hartmann S, Kyewski B, Sonnenburg B, Lucius R (1997) A filarial cysteine protease inhibitor down regulates $T$ cell proliferation and enhances interleukin-10 production. Eur J Immunol 27:2253-2260

Honey K, Rudensky AY (2003) Lysosomal cysteine proteases regulate antigen presentation. Nat Rev Immunol 3(6):472-482

Huo F, Ran C, Yang Y, Hu J, Zhou Z (2016) Gene cloning, expression and characterization of an exo-chitinase with high $\beta$-glucanase activity from aeromonas veronii b565. ACTA Microbiological Sinica 56(5):787-803

Ilgová J, Jedličková L, Dvořáková H, Benovics M, Mikeš L, Janda L, Vorel J, Roudnický P, Potěšil D, Zdráhal Z (2017) A novel type I cystatin of parasite origin with atypical legumain-binding domain. Sci Rep 7:1-12

Jaroenlak P, Boakye DW, Vanichviriyakit R, Williams BA, Sritunyalucksana K, Itsathitphaisarn $\mathrm{O}$ (2018) Identification, characterization and heparin binding capacity of a spore-wall, virulence protein from the shrimp microsporidian, Enterocytozoon hepatopenaei (EHP). Parasit Vectors 11:177

Jenko S, Dolenc I, Gunčar G, Doberšek A, Podobnik M, Turk D (2003) Crystal structure of Stefin A in complex with cathepsin $\mathrm{H}$ : N-terminal residues of inhibitors can adapt to the active sites of endo-and exopeptidases. J Mol Biol 326:875-885

Keilova H, Tomášek V (1974) Effect of papain inhibitor from chicken egg white on cathepsin B1. Biochimica et Biophysica Acta (BBA)-Enzymology 334:179-186

Kelley LA, Mezulis S, Yates CM, Wass MN, Sternberg MJ (2015) The Phyre2 web portal for protein modeling, prediction and analysis. Nat Protoc 10:845

Kumar S, Stecher G, Tamura K (2016) MEGA7: molecular evolutionary genetics analysis version 7.0 for bigger datasets. Mol Biol Evol 33:1870-1874

Laskowski RA, MacArthur MW, Moss DS, Thornton JM (1993) PROCHECK: a program to check the stereochemical quality of protein structures. J Appl Crystallogr 26:283-291

Lecaille F, Kaleta J, Brömme D (2002) Human and parasitic papain-like cysteine proteases: their role in physiology and pathology and recent developments in inhibitor design. Chem Rev 102:4459-4488

Liu Y, YuanJ Jia L, Huang M, Zhou Z, Gu Z (2014) Supplemental description of Thelohanellus wuhanensis Xiao \& Chen, 1993 (Myxozoa: Myxosporea) infecting the skin of Carassius auratus gibelio (Bloch): ultrastructural and histological data. Parasitol Int 63:489-491

Manoury B, Gregory WF, Maizels RM, Watts C (2001) Bm-CPI-2, a cystatin homolog secreted by the filarial parasite Brugia malayi, inhibits class II MHC-restricted antigen processing. Curr Biol 11:447-451 
Medd PG, Chain BM (2000) Protein degradation in MHC class II antigen presentation: opportunities for immunomodulation. Seminars Cell Dev Biol 11:203-210

Nei M, Kumar S (2000) Molecular evolution and phylogenetics. Oxford University Press, Molecular evolution and phylogenetics

Norbury LJ, Hung A, Beckham S, Pike RN, Spithill TW, Craik CS, Choe Y, Fecondo JV, Smooker PM (2012) Analysis of Fasciola cathepsin L5 by S2 subsite substitutions and determination of the P1-P4 specificity reveals an unusual preference. Biochimie 94:1119-1127

Pierce BG, Wiehe K, Hwang H, Kim BH, Vreven T, Weng Z (2014) ZDOCK server: interactive docking prediction of protein-protein complexes and symmetric multimers. Bioinformatics 30:1771-1773

Saitou N, Nei M (1987) The neighbor-joining method: a new method for reconstructing phylogenetic trees. Mol Biol Evol 4:406-425

Salát J, Paesen GC, Řezáčová P, Kotsyfakis M, Kovářová Z, Šanda M, Majtán J, Grunclová L, Horká H, Andersen JF (2010) Crystal structure and functional characterization of an immunomodulatory salivary cystatin from the soft tick Ornithodoros moubata. Biochem J 429:103-112

Sá-Nunes A, Bafica A, Antonelli LR, Choi EY, Francischetti IM, Andersen JF, Kotsyfakis M (2009) The immunomodulatory action of sialostatin L on dendritic cells reveals its potential to interfere with autoimmunity. J Immunol 182(12):7422-7429

Schierack P, Lucius R, Sonnenburg B, Schilling K, Hartmann S (2003) Parasitespecific immunomodulatory functions of filarial cystatin. Infect Immun 71:2422-2429

Schönemeyer A, Lucius R, Sonnenburg B, Brattig N, Sabat R, Schilling K, Bradley J, Hartmann S (2001) Modulation of human T cell responses and macrophage functions by onchocystatin, a secreted protein of the filarial nematode Onchocerca volvulus. J Immunol 167:3207-3215

Shin SP, Jee H, Han JE, Kim JH, Choresca CH Jr, Jun JW, Park SC (2011) Surgical removal of an anal cyst caused by a protozoan parasite (Thelohanellus kitauei) from a koi (Cyprinus carpio). J Am Vet Med Assoc 238(6):784-786

Sigrist CJ, De Castro E, Cerutti L, Cuche BA, Hulo N, Bridge A, Bougueleret L, Xenarios I (2012) New and continuing developments at PROSITE. Nucleic Acids Res 41:D344-D347

Smith D, Tikhonova IG, Jewhurst HL, Drysdale OC, Dvořák J, Robinson MW, Dalton JP (2016) Unexpected activity of a novel kunitz-type inhibitor Inhibition of cysteine proteases but not serine proteases. J Biol Chem 291(37):19220-19234
Steentoft C, Vakhrushev SY, Joshi HJ, Kong Y, Vester-Christensen MB, Katrine T, Schjoldager B, Lavrsen K, Dabelsteen S, Pedersen NB (2013) Precision mapping of the human $O$-GalNAc glycoproteome through simple cell technology. EMBO J 32:1478-1488

Sun Y, Liu G, Li Z, Chen Y, Liu Y, Liu B, Su Z (2013) Modulation of dendritic cell function and immune response by cysteine protease inhibitor from murine nematode parasite $\mathrm{H}$ eligmosomoides polygyrus. Immunology 138:370-381

Turk V, Turk B, Turk D (2001) Lysosomal cysteine proteases: facts and opportunities. EMBO J 20:4629-4633

Tzeng SS, Chen GH, Jiang ST (2002) Expression of soluble thioredoxin fusedcarp (Cyprinus carpio) ovarian cystatin in Escherichia coli. J Food Sci 67:2309-2316

Vray B, Hartmann S, Hoebeke J (2002) Immunomodulatory properties of cystatins. Cell Mol Life Sci CMLS 59:1503-1512

Wang Y, Wen Y, Wang S, Ehsan M, Yan RF (2017) Modulation of goat monocyte function by HCcyst-2, a secreted cystatin from Haemonchus contortus. Oncotarget 8:44108

Yang Y, Xiong J, Zhou Z, Huo F, Miao W, Ran C, Wang M (2014) The genome of the myxosporean Thelohanellus kitauei shows adaptations to nutrient acquisition within its fish host. Genome Biol Evol 6(12):3182-3198

Yap KW, Thompson RC (1987) CTAB precipitation of cestode. DNA. 3:220-222

Ye L, Lu M, Quan K, Li W, Zou H, Wu S, Wang G (2017) Intestinal disease of scattered mirror carp Cyprinus carpio caused by Thelohanellus kitauei and notes on the morphology and phylogeny of the myxosporean from Sichuan Province, southwest China. Chin J Oceanol Limnol 35(3):587-596

Zhao D, Borkhanuddin MH, Wang W, Liu Y, Cech G, Zhai Y, Székely C (2016) The life cycle of Thelohanellus kitauei (Myxozoa: Myxosporea) infecting common carp (Cyprinus carpio) involves aurantiactinomyxon in Branchiura sowerbyi. Parasitol Res 115:4317-4325

\section{Publisher's Note}

Springer Nature remains neutral with regard to jurisdictional claims in published maps and institutional affiliations.

\section{Submit your manuscript to a SpringerOpen ${ }^{\circ}$ journal and benefit from:}

- Convenient online submission

- Rigorous peer review

- Open access: articles freely available online

- High visibility within the field

Retaining the copyright to your article

Submit your next manuscript at $\boldsymbol{\nabla}$ springeropen.com 